\title{
Theranostic nanoparticles based on bioreducible polyethylenimine-coated iron oxide for reduction-responsive gene delivery and magnetic resonance imaging
}

\author{
This article was published in the following Dove Press journal: \\ International Journal of Nanomedicine \\ 10 July 2014 \\ Number of times this article has been viewed
}

\author{
Dan $\mathrm{Li}^{1, *}$ \\ Xin Tang ${ }^{2, *}$ \\ Benjamin Pulli' \\ Chao Lin² \\ Peng Zhao ${ }^{2}$ \\ Jian Cheng ${ }^{2}$ \\ Zhongwei Lv' \\ Xueyu Yuan' \\ Qiong Luo' \\ Haidong Cai' \\ Meng $\mathrm{Ye}^{\mathrm{l}}$ \\ 'Department of Nuclear Medicine, \\ Shanghai I0th People's Hospital, \\ ${ }^{2}$ Shanghai East Hospital, The Institute \\ for Biomedical Engineering and \\ Nanoscience, Tongji University \\ School of Medicine, Tongji University, \\ People's Republic of China \\ *These authors contributed equally \\ to this work
}

Correspondence: Chao Lin Shanghai East Hospital, The Institute for Biomedical Engineering and Nanoscience, Room 222, Shixun Building,

Tongji University, Shanghai, 200092,

People's Republic of China

$\mathrm{Tel}+862165983706803$

Fax +86 2I 659837060

Email chaolin@tongji.edu.cn

Zhongwei Lv

Department of Nuclear Medicine, Shanghai 10th People's Hospital,

30 I Yanchang Road, Shanghai,

200072, People's Republic of China

Email heyixuel63@I63.com

\begin{abstract}
Theranostic nanoparticles based on superparamagnetic iron oxide (SPIO) have a great promise for tumor diagnosis and gene therapy. However, the availability of theranostic nanoparticles with efficient gene transfection and minimal toxicity remains a big challenge. In this study, we construct an intelligent SPIO-based nanoparticle comprising a SPIO inner core and a disulfide-containing polyethylenimine (SSPEI) outer layer, which is referred to as a SSPEI-SPIO nanoparticle, for redox-triggered gene release in response to an intracellular reducing environment. We reveal that SSPEI-SPIO nanoparticles are capable of binding genes to form nano-complexes and mediating a facilitated gene release in the presence of dithiothreitol (5-20 mM), thereby leading to high transfection efficiency against different cancer cells. The SSPEI-SPIO nanoparticles are also able to deliver small interfering RNA (siRNA) for the silencing of human telomerase reverse transcriptase genes in HepG2 cells, causing their apoptosis and growth inhibition. Further, the nanoparticles are applicable as T2-negative contrast agents for magnetic resonance (MR) imaging of a tumor xenografted in a nude mouse. Importantly, SSPEI-SPIO nanoparticles have relatively low cytotoxicity in vitro at a high concentration of $100 \mu \mathrm{g} / \mathrm{mL}$. The results of this study demonstrate the utility of a disulfide-containing cationic polymer-decorated SPIO nanoparticle as highly potent and low-toxic theranostic nano-system for specific nucleic acid delivery inside cancer cells.
\end{abstract}

Keywords: nanoparticles, SSPEI, hTERT, disulfide, RNA interference, tumor, MR imaging

\section{Introduction}

Gene therapy offers great promise in the treatment of overwhelming human diseases such as genetic disorders, cancer, and AIDS. ${ }^{1}$ Although recombinant viral vectors have been studied extensively for gene delivery in vitro and in clinical trials, their bio-safety including immunogenicity, mutagenesis, and oncogenicity remains a major concern and thus seriously impedes their subsequent clinical translation. ${ }^{2}$ As alternatives to viral vectors, non-viral vectors, such as cationic polymers and cationic nanoparticles, have been studied for non-viral gene delivery because of their relatively safe profiles and additional advantages in facile preparation, unlimited gene-carrying capacity, and large-scale production at low cost. ${ }^{3-6}$ However, the critical challenges remain for non-viral vectors due to high cytotoxicity and/or inferior transfection efficacy as compared to viral vectors.

In order to achieve successful gene therapy, non-viral vectors must circumvent a series of gene delivery barriers such as cellular membrane, endosomes/lysosomes, and vector unpacking. ${ }^{7}$ Thus far, a lot of cationic polymers such as polyethylenimine 
(PEI) and polyamidoamine dendrimers ${ }^{8}$ have been studied that can bind genes to form nano-polyplexes and induce efficient endosomal escape, underlying a mechanism such as the "proton sponge" effect. ${ }^{9}$ Besides, for reduced toxicity, biodegradable cationic polymers have been developed in recent years. ${ }^{2}$ Particularly, there is rapidly increasing research on the synthesis of bioreducible (disulfide-based) cationic polymers such as non-viral gene delivery vectors. ${ }^{10-12}$ For example, bioreducible PEI (SSPEI) was recently prepared by disulfide-crosslinking of low-molecular-weight PEI and applied for DNA/small interfering RNA (siRNA) delivery. ${ }^{13,14}$ It is confirmed that the disulfide bond is relatively chemically stable extracellularly, but biodegradable intracellularly due to the presence of the glutathione, since its concentration is 100 to 1,000 times higher $(2-10 \mathrm{mM})$ as compared to that in the extracellular environment $(2-20 \mu \mathrm{M}) .{ }^{10}$ Therefore, bioreducible cationic polymers are degradable in the cellular interior by disulfide bond cleavage, causing adequate dissociation of polymer-gene complexes and subsequent gene release, thereby leading to an enhanced level of gene expression. An additional merit of this degradation process is diminished cytotoxicity for bioreducible polycations as a result of low charge density of degraded pieces. Accordingly, disulfide-based cationic polymers have a high potential as safe and efficient non-viral gene carriers. ${ }^{11}$

There has been significant progress in the preparation of magnetic nanoparticles as well as their biomedical application in gene delivery. For example, superparamagnetic iron oxide (SPIO) nanoparticles coated with PEI (PEI-SPIO) were prepared by a co-precipitation method and applied for efficient gene delivery to cancer cells. ${ }^{15-17}$ However, PEI-coated SPIO nanoparticles normally have a high cytotoxicity due to their high charge density. ${ }^{16}$ To address this issue, Kievit et al prepared chitosan-modified PEI-SPIO nanoparticles having reduced charge density, causing low cytotoxicity against C6 cells. ${ }^{18}$ In another work, Chen et al reported on PEG-modified $25 \mathrm{k}$ PEI-SPIO nanoparticles that had low cytotoxicity against SGC-7901 cells. ${ }^{19}$ Furthermore, these SPIO nanoparticles are effective for magnetic resonance (MR) imaging in vivo. Because of gene transfer and MR imaging dual functions, cationic SPIO nanoparticles are valuable theranostic nano-systems. ${ }^{20-24}$ However, these SPIO nanoparticles reported to date lack the ability to mediate efficient intracellular gene release as an innate gene delivery barrier. Accordingly, there is a fundamental need to develop a "smart" SPIO nano-system which can mediate an efficient gene release in response to a stimulus, eg, intracellular reducing environment.
Therefore, the aim of this study is the construction of bioreducible cationic polymer-coated SPIO nanoparticles and their evaluation for DNA/siRNA delivery and MR imaging. To this end, SSPEI, a disulfide-based polycation, was incorporated into SPIO nanoparticles, generating SSPEI-SPIO nanoparticles comprised of a SPIO inner core and SSPEI outer layer (Figure 1). We hypothesize that SSPEI-SPIO nanoparticles may be efficient as non-viral gene vectors for intracellular DNA and siRNA delivery. Herein, we investigated physiochemical and biophysical properties of SSPEI-SPIO nanoparticles in terms of size, surface charge, magnetism, gene binding and release, and in vitro transfection efficiency as well as biodistribution. The utility of SSPEISPIO nanoparticles as contrast agents for MR imaging of tumors was also evaluated in a mouse model.

\section{Material and methods Materials}

The chemicals, low molecular weight polyethylenimine $(800 \mathrm{Da})$, branched polyethylenimine (B-PEI, $\left.\mathrm{M}_{\mathrm{w}}=25 \mathrm{k} \mathrm{Da}\right)$, 1-(3-Dimethylaminopropyl)-3-ethylcarbodiimide hydrochloride (EDC), N-hydroxysuccinimide (NHS), 3,3'dithiobispropanoic acid, 2-[4-(2-hydroxyethyl)piperazin-1-yl] ethane sulfonic acid (HEPES), dithiothreitol (DTT), 2-(Nmorpholino)ethanesulfonic acid (MES), poly(acrylic acid) (PAA, $\left.\mathrm{M}_{\mathrm{w}}=1,800\right)$ and anhydrous iron chloride $\left(\mathrm{FeCl}_{3}\right)$ were purchased from Sigma-Aldrich Co. (St Louis, MO, USA). Near-infrared fluorescent dye Cy5.5-NHS was ordered from Beijing FanBo Co. (Beijing, People's Republic of China). Plasmid pCMV-GFP encoding green fluorescent protein (GFP) gene under the control of a cytomegalovirus (CMV) promoter was purchased from the PlasmidFactory $\mathrm{GmbH}$ \& Co. KG (Bielefeld, Germany). Four double-stranded siRNA targeting human telomerase reverse transcriptase (hTERT) gene and one non-silencing siRNA (siRNA-NC) sequence were synthesized and purchased by GenePharma Co. (Shanghai, People's Republic of China) as follows, ie, name (TERT gene target location): sequence (guaninecytosine $[\mathrm{G} / \mathrm{C}]$ content $\%)$ :

hTERT-siRNA1 sense sequence (966): 5'-CGGUGUA CGCCGAGACCAAdTdT-3' (57\%)

hTERT-siRNA2 sense sequence (1163): 5'-AUGCCGCC CCUGUUUCUGGdTdT-3' (57\%)

hTERT-siRNA3 sense sequence (2862): 5'-CCAGAAACA GGGGCCGCAUdTdT-3' (47\%)

hTERT-siRNA4 sense sequence (2905): 5'-CAUGCGUC GCAAACUCUUUdTdT-3' (43\%) 


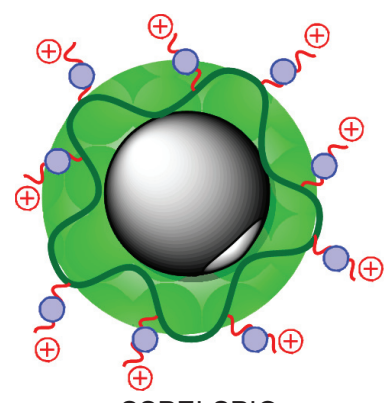

SSPEI-SPIO

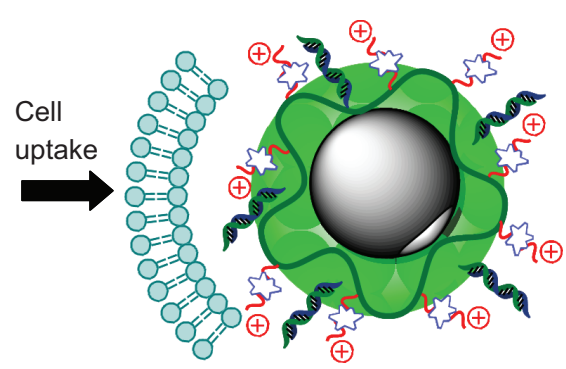

Cellular membrane

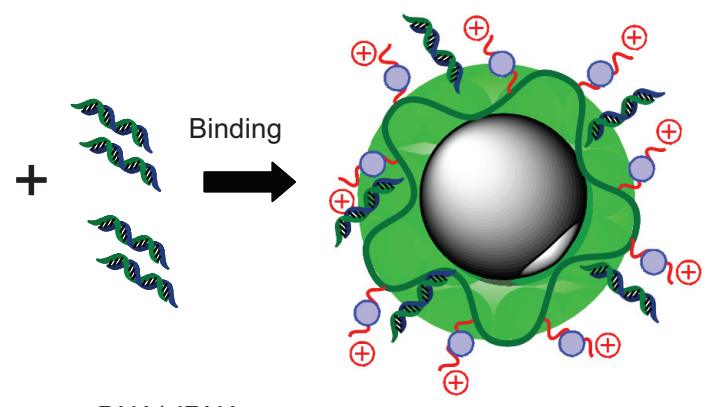

DNA/siRNA

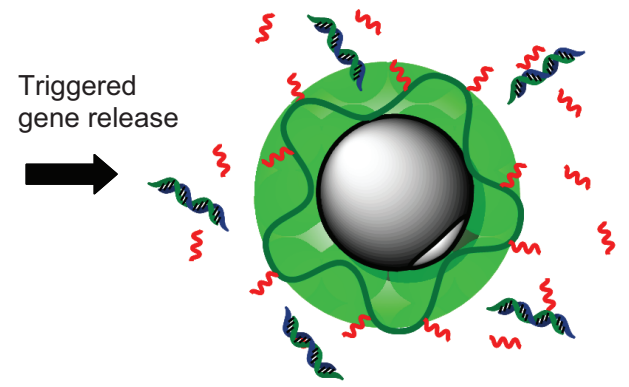

๑ sSPEl

Iron oxide

?

Polyacrylic acid (PAA) $\sum^{n}$ Disulfide cleavage

Figure I Schematic illustration of SSPEI-SPIO nanoparticles, which efficiently bind genes and mediate subsequent gene release triggered by an intracellular reducing environment.

Abbreviations: SPIO, superparamagnetic iron oxide; SSPEI, disulfide-containing polyethylenimine; siRNA, small interfering RNA.

siRNA-NC sense sequence: 5'-GGCCUCAGCUGC GCGACGCdTdT-3' (47\%)

PAA-coated SPIO nanoparticles were synthesized by onepot hydrolysis reaction of anhydrous $\mathrm{FeCl}_{3}$ at $200^{\circ} \mathrm{C}$ in the presence of PAA, via the protocol reported previously. ${ }^{25}$ The content of carboxylic acid $(\mathrm{COOH})$, determined by acid-base titration assay, in PAA-coated SPIO is $\sim 7 \mathrm{mmol} / \mathrm{g} .{ }^{26} \mathrm{SSPEI}$ was synthesized by the coupling of an equimolar ratio of 3,3'-dithiobispropanoic acid and low molecular weight polyethylenimine (800 Da) via an EDC/NHS activation reaction as reported previously. ${ }^{13}$

\section{Synthesis of SSPEI-SPIO nanoparticles}

SSPEI-SPIO nanoparticles were prepared by coupling different amounts of the SSPEI to SPIO via an EDC/NHS activation reaction. In a typical procedure, SPIO nanoparticles in a MES buffer (20 mM, pH 6.5) solution ( $0.7 \mathrm{mmol} \mathrm{COOH} /$ $\mathrm{mL}, 100 \mu \mathrm{L}$ ) were mixed with the SSPEI in the MES buffer solution $(0.7 \mathrm{mmol} \mathrm{NH} 2 / \mathrm{mL}, 25-6000 \mu \mathrm{L})$ in a round-bottle flask and the mixture was stirred for 1 hour at room temperature. Next, EDC $(0.065 \mathrm{mmol} / \mathrm{mL}, 150 \mu \mathrm{L})$ and NHS $(0.065 \mathrm{mmol} / \mathrm{mL}, 150 \mu \mathrm{L})$ in the MES buffer solution were added in the flask and the reaction proceeded overnight.
The resulting solution was purified by exhaustive dialysis (10 kg/mol cut-off) using $50 \mathrm{mM} \mathrm{NaCl}$ solution $(3 \times 5 \mathrm{~L})$ and deionized water $(18.2 \Omega, 3 \times 5 \mathrm{~L})$. SSPEI-SPIO nanoparticles were obtained as a solid powder after freeze-drying (yield: $25 \%-45 \%$ ).

Cy5.5-labeled SSPEI-SPIO nanoparticles were prepared by coupling NHS-activated Cy5.5 with the nanoparticles. In brief, SSPEI-SPIO nanoparticles $(10 \mathrm{mg})$ and NHS-Cy 5.5 (200 nmol in dimethyl sulfoxide) were added into a flask and stirred in a MES buffer ( $\mathrm{pH} 6.5,5 \mathrm{~mL}$ ) for 2 days at room temperature. The resulting solution was purified by exhaustive dialysis $(3,500 \mathrm{~g} / \mathrm{mol}$ cut-off) for 3 days. Cy5.5-labeled SSPEI-SPIO nanoparticles were obtained as a solid powder after freeze-drying (yield: 93\%). The amount of Cy5.5 in the nanoparticles was calculated using a UV-calibration curve from different Cy5.5 concentration solutions.

\section{Characterization of SSPEI-SPIO nanoparticles}

The shape of the SSPEI-SPIO nanoparticles was observed by atom force microscopy (SPM-9600, Shimadzu Corp., Kyoto, Japan) at ambient temperature in tapping mode using a scanning probe with the constant force of $40 \mathrm{~N} / \mathrm{m}$ at a resonant frequency of $170 \mathrm{kHz}$. The functional groups in 
SSPEI-SPIO nanoparticles were characterized by a Fourier transform infrared spectrometer (Bruker Tensor 27, Bruker, Woodlands, TX, USA). Particle size and zeta potential of SSPEI-SPIO nanoparticles were measured by dynamic light scattering analysis. The content of the amino group in SSPEI-SPIO was determined by 2,4,6-trinitrobenzene sulfonic acid assay.

The magnetic property of SSPEI-SPIO nanoparticles was characterized by a vibrating sample magnetometer (7407 VSM; Lake Shore Cryotronics, Inc., Westerville, OH, USA) applied with a magnetic field of $\pm 20 \mathrm{k}$ Oe (Oersted units of magnetic energy) at $300 \mathrm{~K}$. The mass magnetization is defined as magnetic moment per sample mass (in electromagnetic units, emu/g sample) as the sample is placed in a changing magnetic field.

T2-weighted imaging of SSPEI-SPIO nanoparticles is performed using 1.5-T clinical magnet (Bruker) equipped with a Varian Inova spectrometer (Varian Inc., Cary, NC, USA) and an in-house built $10 \mathrm{~cm}$ RF coil in a loop gap resonator type with a conventional multi-spin echo pulse sequence $(\mathrm{TR}=3,000 \mathrm{~ms}, \mathrm{TE}=16,20,40,60,90 \mathrm{~ms})$. In brief, SSPEI-SPIO nanoparticles were diluted in $1 \times$ phosphate buffered saline (PBS) buffer ( $\mathrm{pH} 7.4$ ), mixed with $200 \mu \mathrm{L}$ of melting $0.7 \%$ agarose gel, and added into each well of a 24-well plate until the solution solidification. The final $\mathrm{Fe}$ concentrations were set as $0.023,0.045,0.09,0.18,0.36 \mathrm{mM}$. MR imaging T2 value was calculated from a series of echo time (TE) images with standard procedures according to manufacturer's instruction.

\section{Agarose gel electrophoresis analysis of SSPEI-SPIO/DNA complexes}

The complexes of SSPEI-SPIO/DNA were prepared by gentle mixing of a HEPES buffer solution $(20 \mathrm{mM}$, $\mathrm{pH} 7.4)$ of SSPEI-SPIO (10 $\mu \mathrm{L}$, different concentrations $)$ and DNA $(10 \mu \mathrm{L}, 80 \mu \mathrm{g} / \mathrm{mL})$, followed by 5 seconds pipetting. The mixtures were incubated for 30 minutes at room temperature. After the addition of $2 \mu \mathrm{L}$ of $6 \times$ loading buffer (Fermentas, Leon-Rot, Germany), $10 \mu \mathrm{L}$ of the mixture or DNA (as a control) was loaded onto a $0.7 \%$ agarose gel with ethidium bromide (EB). After running gel electrophoresis at $100 \mathrm{mV}$ for 30-45 minutes, DNA was visualized under a UV lamp and captured by Tanon Gel Image system (Thermo Fisher Scientific, Waltham, MA, USA). To analyze gene release in a reducing environment, the complexes were coincubated with $10 \mu \mathrm{L}$ of DTT-containing HEPES buffer (final DTT concentration of 5 or $20 \mathrm{mM}$ ) for 30 minutes. Then, the DNA band was visualized and captured by the system.

\section{Particle size and zeta-potential measurements of SSPEI-SPIO-based complexes}

The complexes of SSPEI-SPIO nanoparticle/DNA (siRNA) were prepared by mixing SSPEI-SPIO solution $(800 \mu \mathrm{L}$, 187.5 or $375 \mu \mathrm{g} / \mathrm{mL}$, HEPES buffer, $20 \mathrm{mM}, \mathrm{pH} 7.4$ ) with a DNA (siRNA) solution ( $200 \mu \mathrm{L}, 75 \mu \mathrm{g} / \mathrm{mL}$, HEPES buffer, $20 \mathrm{mM}, \mathrm{pH}$ 7.4), which affords a SSPEI-SPIO/DNA (siRNA) mass ratio of 10:1 and 20:1, respectively, followed by gentle vortexing and standing for 30 minutes at room temperature. Particle size and surface charge of the complexes were measured by a Nanosizer NS90 (Malvern Instruments, Malvern, UK) at $25^{\circ} \mathrm{C}$.

\section{EB accessibility assay}

DNA binding and release behaviors of SSPEI-SPIO nanoparticles were evaluated by EB (Sigma-Aldrich Co.) accessibility assay. In brief, DNA $(2 \mu \mathrm{g})$ and $\mathrm{EB}(0.25 \mu \mathrm{g})$ were dissolved in HEPES buffer $(25 \mu \mathrm{L}, 20 \mathrm{mM}$, pH 7.4). The complexes of SSPEI-SPIO60 nanoparticle/EB-DNA were prepared by adding EB-DNA $(10 \mu \mathrm{L})$ into SSPEI-SPIO60 $(10 \mu \mathrm{L}$, different concentrations), 5 seconds pipetting, and 30 minutes standing at room temperature. Next, the complex mixture $(10 \mu \mathrm{L})$ and EB-DNA $(10 \mu \mathrm{L})$ were transferred into a 96-well plate. The fluorescence intensity of the samples $\left(\mathrm{F}_{\mathrm{C}}\right)$ and EB-DNA $\left(\mathrm{F}_{\mathrm{EB}}\right)$ was recorded using a fluorescence plate-reader meter (Thermo Fisher Scientific) with the excitation and emission wavelengths of 488 and $590 \mathrm{~nm}$, respectively. Relative fluorescence intensity $\left(\mathrm{F}_{\mathrm{REL}}\right)$ of the samples was calculated with the equation:

$$
\mathrm{F}_{\mathrm{REL}}(\%)=100 \times\left(\mathrm{F}_{\mathrm{C}}-\mathrm{F}_{0}\right) /\left(\mathrm{F}_{\mathrm{EB}}-\mathrm{F}_{0}\right),
$$

wherein $\mathrm{F}_{0}$ is the fluorescence intensity of the HEPES buffer as a blank. To characterize gene release in a mimicking reducing environment, the complexes $(10 \mu \mathrm{L})$ were incubated with $20 \mathrm{mM}$ DTT in the HEPES buffer for 30 minutes, $\mathrm{F}_{\mathrm{C}}$ was recorded with a fluorescence meter, and $\mathrm{F}_{\mathrm{REL}}$ was calculated using Equation 1.

\section{Gene transfection in vitro, gene expression and cell viability assay}

MCF-7 cells, PC-3, SKOV-3 and HepG2 cells (American Type Culture Collection [ATCC], Manassas, VA, USA) were grown in full culture medium (ie, Dulbecco's Modified Eagle's Medium [DMEM] supplemented with $10 \%$ fetal bovine serum [FBS], $100 \mathrm{U} / \mathrm{mL}$ penicillin and streptomycin [Gibco ${ }^{\circledR}$, Thermo Fisher Scientific]) at $37^{\circ} \mathrm{C}$ 
in a humidified 5\% $\mathrm{CO}_{2}$-containing atmosphere. An in vitro gene transfection experiment was performed using pCMV-GFP plasmid encoding GFP gene under a control of a CMV promoter.

\section{SSPEI-SPIO-mediated DNA transfection against MCF-7 cells}

MCF-7 cells $\left(7 \times 10^{4}\right.$ cells/well $)$ were plated in a $24-$ well plate and allowed to grow at least 24 hours until 60\%-70\% cell confluence. In a typical DNA transfection, first, SSPEI-SPIO and DNA $(1 \mu \mathrm{g})$ were mixed in a HEPES buffer $(20 \mathrm{mM}, \mathrm{pH}$ 7.4) and co-incubated at an ambient temperature for $30 \mathrm{~min}$ utes. The SSPEI-SPIO/DNA mass ratios were varied in the range from 1:1 to 20:1. Next, the cells were washed twice with fresh $1 \times$ PBS buffer, cultured in a FBS-free DMEM medium $(500 \mu \mathrm{L})$, and co-incubated with the complexes of SSPEI-SPIO/DNA $(50 \mu \mathrm{L})$ at $37^{\circ} \mathrm{C}$ in a $5 \% \mathrm{CO}_{2}$-containing atmosphere. After 1 hour co-incubation, the medium was replaced with a full culture growth medium and the cells were cultured for another 47 hours post-transfection. The formulation of B-PEI/DNA at an optimal N:P ratio of 8:1 was applied as a positive control. The cells without transfection were used as a blank control.

\section{SSPEI-SPIO-mediated hTETR-siRNA transfection in HepG2 cells}

HepG 2 cells $\left(7 \times 10^{4}\right.$ cells/well) were plated in a $24-$ well plate and allowed to grow at least 24 hours until $60 \%-70 \%$ cell confluence. In a typical siRNA protocol, SSPEI60-SPIO (in sterilized HEPES buffer, $20 \mathrm{mM}, \mathrm{pH}$ 7.4) and siRNA ( $0.5 \mu \mathrm{g}$ in diethylpyrocarbonate water) were mixed at an optimal N:P ratio of 10:1 and incubated at room temperature for 30 minutes. HepG2 cells were then washed with fresh $1 \times$ PBS buffer, cultured in a FBS-free DMEM medium $(500 \mu \mathrm{L})$, and co-incubated with the diluted SSPEI-SPIO/ siRNA mixture $(50 \mu \mathrm{L})$ for 4 hours transfection. Finally, the cells were cultured in fresh full culture medium for another 44 hours. As a positive control, a formulation of Lipofectamine 2000 (Lipo 2000; Life Technologies, Waltham, MA, USA)/siRNA at an optimal ratio ( $1 \mu \mathrm{L}+1 \mu \mathrm{g}$ siRNA) was also applied.

\section{Transfection efficiency assay by GFP expression and flow cytometry}

The transfection efficiency was measured to quantify GFP expression in cells. After transfection, the cells in each well were washed twice with $1 \times$ PBS and incubated with cell lysis buffer $(200 \mu \mathrm{L})$. The cell lysates were collected, centrifuged to pellet the cellular debris, and cell lysate $(100 \mu \mathrm{L})$ was used to determine fluorescence intensity of GFP with excitation and emission wavelengths of 488 and $520 \mathrm{~nm}$, respectively (Thermo Fisher Scientific). Background fluorescence and auto-fluorescence were determined using untreated cells as a blank control. The total recovered protein concentration in the cell lysate from each well was estimated using a bicinchoninic acid protein assay kit (Invitrogen, Thermo Fisher Scientific). GFP expression is calculated as fluorescence intensity normalized against protein concentration and shown as the arbitrary units/mg protein. The results show mean \pm deviation for triplicate samples.

Transfection efficiency was also determined using flow cytometry (BD Biosciences, San Jose, CA, USA). In brief, after alamarBlue ${ }^{\circledR}$ (Life Technologies) assay, the medium was discarded and the cells were washed twice with $1 \times$ PBS buffer, trypsinized, transferred to sterile tubes, and centrifuged at $800 \mathrm{rmp}$ for 5 minutes at $4^{\circ} \mathrm{C}$. The supernatant was poured off, and the cells were re-suspended in $0.4-1 \mathrm{~mL}$ of $1 \times$ PBS containing $1 \%$ FBS. Next, $10 \mu \mathrm{L}$ of propidium iodide (PI, $1.0 \mathrm{mg} \mathrm{mL}^{-1}$ ) was added to the cells to determine cell viability. Fluorescence for GFP and PI were detected using a flow cytometer (BD Biosciences). The cytometer was calibrated with untreated cells to identify viable cells and blank transfection efficiency. The percentages of GFP-expressing cells were quantified from a gated viable population of 10,000 cells. The viable cells were gated based on cell exclusion of PI in all experiments.

\section{Reverse transcription and polymerase chain reaction of $h T E R T$ gene}

HepG 2 cells were collected at 48 hours after siRNA transfection mediated by SSPEI-SPIO nanoparticles. Total RNA was harvested using TRIzol Reagent (Invitrogen) from cell lysis via a standard chloroform-extraction protocol. Complementary DNA (cDNA) was synthesized via the First-strand cDNA synthesis kit (RevertAidTM, Fermentas). The polymerase chain reaction (PCR) for hTERT was run according to our previous protocol. ${ }^{13}$

For hTERT primers, the sense sequence is $5^{\prime}$-CTACGG CGACATGGAGAACAAGC-3', and the anti-sense sequence is $5^{\prime}$-CGCAGCCATACTCAGGGACAC-3'. For $\beta$-actin (as a house-keeping gene) primers, the sense sequence is 5'-CCTGGCACCCAGCACAATGAAG-3', and anti-sense sequence is 5'-GGGGCCGGACTCGTCATACTC-3' (Sangon Biotech [Shanghai] Co., Ltd, Shanghai, People's Republic of China). 


\section{Western blot assay}

HepG2 cells were collected at 48 hours after siRNA transfection mediated by SSPEI-SPIO nanoparticles. HepG2 cells were lysed in an ice-cold lysis buffer cocktail containing 1\% Triton X-100 (Sigma-Aldrich Co.). Next, protein extracts were loaded into a $12.5 \%$ sodium dodecyl sulfate/ polyacrylamide gel, electrophoresed, and transferred to a nitrocellulose membrane. After blocking with 5\% non-fat dry milk, the membrane was washed in a Tris-buffered saline/Tween-20 mixture and co-incubated with a rabbit anti-hTERT primary mon-clonal antibody (Santa Cruz Biotechnology Inc., Santa Cruz, CA, USA) diluted at 1:500 in a $5 \%$ milk at $4{ }^{\circ} \mathrm{C}$ overnight. The blot was then washed again in Tris-buffered saline/Tween-20 and incubated for 1 hour with horseradish peroxidase-conjugated donkey anti-rabbit IGg secondary antibody (Santa Cruz Biotechnology Inc.) diluted at 1:3000 in 5\% milk. The blot signal was detected using Image Station 2000 MM System (Kodak, NY, USA) and analyzed with Kodak Molecular Imaging Software (Standard Edition V 5.0).

\section{Cell viability assay}

Cell viability was measured by an alamarBlue ${ }^{\circledR}$ assay. ${ }^{27,28} \mathrm{In}$ brief, after 48 hours of transfection, the cells (and untreated cells) were washed twice with fresh $1 \times$ PBS buffer and incubated with $500 \mu \mathrm{L}$ of fresh-made $1 \times$ alamarBlue ${ }^{\circledR}(10 \times)$ diluted in RPMI 1640 media (Life Technologies) (without phenol red) for 4 hours. Then, $200 \mu \mathrm{L}$ of the medium from each well (also $1 \times$ alamarBlue ${ }^{\circledR}$-RPMI 1640 medium as a blank) were transferred to a $96-$ well plate for plate reading. The absorbance density (OD) was measured using a plate reader (Thermo Fisher Scientific) at the wavelength of $570 \mathrm{~nm}$ and $630 \mathrm{~nm}$, respectively.

As to the evaluation of cytotoxicity of SSPEI-SPIO nanoparticles, MCF-7 cells $\left(1 \times 10^{4}\right.$ cells/well $)$ were plated in a 96-well plate and allowed to grow at least 24 hours until $60 \%-70 \%$ cell confluence. The cells were co-incubated with the nanoparticles at different concentrations in a culture medium without FBS for 1 hour. Next, the cells were cultured in a full culture medium for another 47 hours. SSPEI and B-PEI were also tested as controls. Cell viability was evaluated by an alamarBlue ${ }^{\circledR}$ assay.

Cell viability was calculated with the equation:

$$
\text { (ODsample-OD0)/ODcontrol-OD0) } \times 100 \text {, }
$$

in which ODsample, ODcontrol, and OD0 are OD values of the medium of transfected cells, the medium of untreated cells (control), and $1 \times$ alamarBlue ${ }^{\circledR}$-RPMI 1640 medium, respectively. The calculated value for untreated cells as a control was taken as $100 \%$ cell viability.

\section{Flow cytometry for cell apoptosis detection}

The siRNA transfection was conducted using SSPEI-SPIO nanoparticles. After 48 hours of transfection, HepG2 cells were trypsinized, harvested, and washed with $1 \times$ PBS. Then, the cells were stained with Annexin V-FITC and PI using Annexin V-FITC Apoptosis Detection Kit (BD Biosciences). The percentage of apoptotic cells was quantified by a flow cytometry (BD Biosciences). Annexin-V positive and PI negative indicate early apoptosis, while both Annexin V-FITC and PI positive indicate late apoptosis. The results are mean \pm standard deviation for triplicate samples.

\section{Near infrared imaging of tumor bearing in nude mouse with Cy5.5-labeled SSPEI-SPIO}

The animal experiments were officially approved by Tongji University (Shanghai, People's Republic of China). Five to six week-old male BALB/c nude mice were purchased from SLAC Laboratory Animals (Shanghai, People's Republic of China). HepG2 tumors were induced in the mice by subcutaneously injecting HepG2 cells $\left(5.0 \times 10^{6}\right)$ into the flank of the mice. As the tumor volume reached to $\sim 400 \mathrm{~mm}^{3}$, Cy5.5-labeled SSPEI-SPIO nanoparticles were intravenously (IV) administrated by tail-vein injection. The total amount of Cy5.5 in the nanoparticles was determined to be $1,760 \mathrm{pmol}$. At regular time intervals, in vivo imaging of the tumor site was conducted by quantitative fluorescence tomography imaging system (FMT2500; PerkinElmer Inc., Waltham, MA, USA). The excitation and emission wavelengths used for the imaging were 670 and 690-740 nm, respectively. For ex vivo imaging of isolated tumors and organs, heart, lungs, liver, spleen, and kidneys were collected at 1 hour post-IV injection and scanned for ex vivo imaging with the FMT2500 system. The amount of Cy5.5 in the tumor and each organ was determined by a reconstruction software (True Quant ${ }^{\mathrm{TM}}$ 3D, Version 2.0.0.19, PerkinElmer Inc., Waltham, MA, USA), according to the manufacturer's instruction. The accumulated percentage of injection dose of SSPEI-SPIO nanoparticles in the tumor (organ) was calculated as the percentage of the amount of Cy5.5 in the tumor (organ) relative to the total amount of Cy5.5 (1,760 pmol) in injected nanoparticles. The data are presented as the means \pm $\mathrm{SD}$ values of triplicate samples in three independent experiments. 


\section{MR imaging of HepG2 tumor-bearing in a nude mouse with SSPEI-SPIO}

HepG2 tumor-xenografted nude mice were administrated by tail-vein injection with the SSPEI60-SPIO nanoparticles at a dose of $0.5 \mathrm{mg} / \mathrm{kg}$, then placed in an acrylic holder and positioned in the magnet center of a clinical 3.0 T MR instrument (Siemens, Munich, Germany). After 1, 2, and 3 hourspost-IV injection, T2-weighted MR imaging of the mice was recorded at the parameters: TR/TE 4,000 ms/89 ms, matrix size $179 \times 256$, field of view $59 \times 59 \mathrm{~mm}$.

\section{Prussian blue staining}

The tumor/organ tissue sections were rinsed in distilled water, incubated for 45 minutes in an aqueous solution of $2 \%$ potassium ferrocyanide and $2 \%$ hydrochloric acid $(1: 1$, volume/volume), rinsed again and finally observed under optical microscopy at $200 \times$ magnification (Nikon Corporation, Tokyo, Japan).

\section{Statistical analysis}

Analysis was performed using SPSS for Windows XP (SPSS v19.0, IBM Corporation, Armonk, NY, USA). Differences were considered to be statistically significant at $P<0.05$ (Student's $t$-test).

\section{Results}

\section{Preparation and characterization of SSPEI-SPIO nanoparticles}

SSPEI-SPIO nanoparticles were readily prepared by chemical conjugation of the primary amine $\left(\mathrm{NH}_{2}\right)$ of SSPEI to $\mathrm{COOH}$ of PAA-coated SPIO nanoparticles via an EDC/NHS activation reaction (Figure $2 \mathrm{~A}$ ). The reaction was performed in

\section{A}
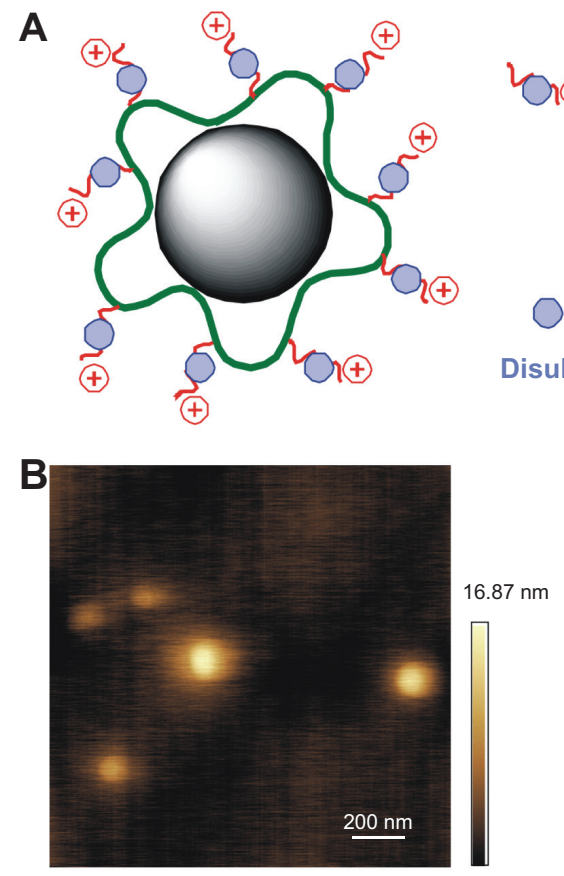

D - sspeI — SPIO — SSPEI60-SPIO

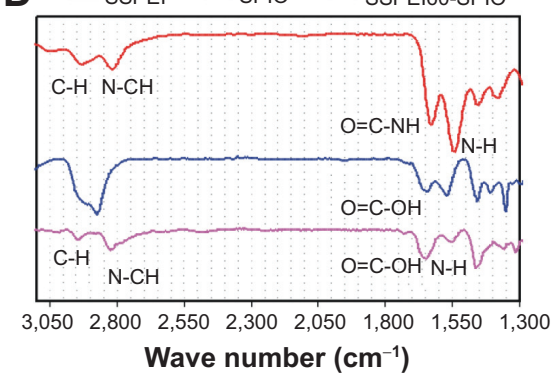

$\mathrm{Or}$

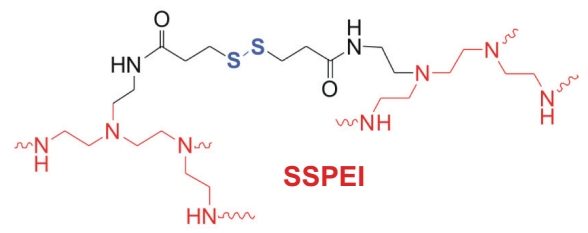

Disulfide

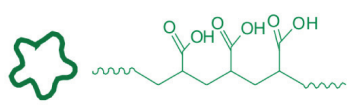

PAA

SPIO
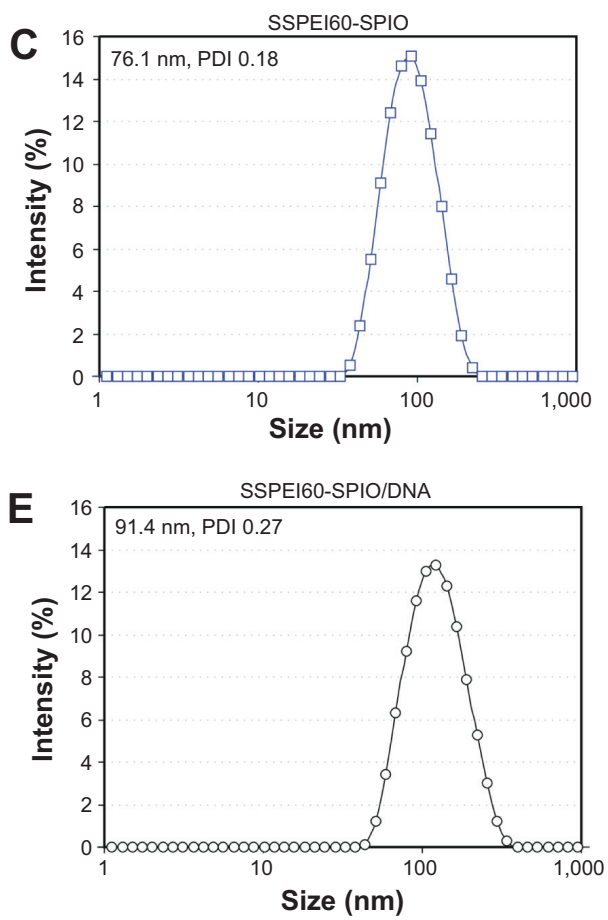

Figure 2 (A) Illustration of the structure and component of SSPEI-SPIO nanoparticles; (B) atom force microscopy images of SSPEI60-SPIO nanoparticles; (C) size distribution of SSPEI60-SPIO nanoparticles in deionized water; (D) Fourier transform infrared spectra of SSPEI, SPIO and SSPEI60-SPIO nanoparticles; (E) size distribution of SSPEI60SPIO/DNA complexes at a mass ratio of I0:I in HEPES buffer (20 mM, pH 7.4).

Abbreviations: SPIO, superparamagnetic iron oxide; SSPEI, disulfide-containing polyethylenimine; HEPES, 2-[4-(2-hydroxyethyl)piperazin-I-yl]ethane sulfonic acid; PAA, poly(acrylic acid); PDI, polydispersity index. 
Table I Characteristics of PAA-coated SPIO and SSPEI-SPIO nanoparticles

\begin{tabular}{llllll}
\hline No & Acronym & $\begin{array}{l}\text { Feed ratio of } \\
\mathbf{N H}_{\mathbf{2}} / \mathbf{C O O H}\end{array}$ & $\begin{array}{l}\text { Size } \\
(\mathbf{n m})\end{array}$ & $\begin{array}{l}\text { Zeta potential } \\
(\mathbf{m V})\end{array}$ & $\begin{array}{l}\text { Amine content } \\
\left(\times 1 \mathbf{0}^{-3} \mathbf{~ m m o l} / \mathbf{m g}\right)\end{array}$ \\
\hline 1 & 0 & $59.5 \pm 0.6$ & $-26.4 \pm 0.7$ & $\mathrm{n} / \mathrm{a}$ \\
2 & SPIO & $0.8: 1$ & $177.4 \pm 7.8$ & $+8.4 \pm 2.5$ & 0.21 \\
3 & SSPEI0.8-SPIO & $12: 1$ & $97.5 \pm 1.8$ & $+15.3 \pm 1.6$ & 0.47 \\
4 & SSPEII2-SPIO & $20: 1$ & $98.8 \pm 1.3$ & $+18.6 \pm 0.6$ & 0.56 \\
5 & SSPEI20-SPIO & $60: 1$ & $76.1 \pm 1.7$ & $+26.3 \pm 0.5$ & 1.03 \\
\hline
\end{tabular}

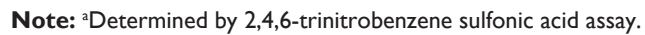

Abbreviations: PAA, poly(acrylic acid); SPIO, superparamagnetic iron oxide; SSPEI, disulfide-containing polyethylenimine; n/a, not applicable.

the MES buffer ( $\mathrm{pH}$ 6.5) with different molar feed ratios of $\mathrm{NH}_{2} / \mathrm{COOH}$, in order to modulate the SSPEI amount of SSPEI-SPIO nanoparticles (Table 1). The SSPEI-SPIO nanoparticles were obtained as a solid powder after exhaustive dialysis (10,000 molecular weight cut-off) and freezedrying. These nanoparticles had good solubility in HEPES and PBS buffer saline ( $\mathrm{pH}$ 7.4) at a tested concentration of $5 \mathrm{mg} / \mathrm{mL}$. Atom force microscopy revealed that SSPEI-SPIO nanoparticles displayed spherical shape with the particle sizes in tens of nanometers (Figure 2B). In addition, dynamic light scatting analysis revealed that these nanoparticles had average hydrodynamic sizes ranging from about 76 to $177 \mathrm{~nm}$ (Table 1) with a relatively narrow particle size distribution (polydispersity index of 0.16-0.18) (Figure 2C). By increasing the $\mathrm{NH}_{2} / \mathrm{COOH}$ feed ratios from 0.8:1 to 60:1, the hydrodynamic sizes of these nanoparticles markedly decreased from $\sim 177 \mathrm{~nm}$ to $\sim 76 \mathrm{~nm}$ and their surface charges augmented from $+8.4 \pm 2.5 \mathrm{mV}$ to $+26.3 \pm 0.5 \mathrm{mV}$ (Table 1). The positive charge implies that the SSPEI-SPIO nanoparticles possess a positive SSPEI outer layer instead of a negative PAA layer $(-26.4 \pm 0.7 \mathrm{mV})$ of original SPIO nanoparticles. In addition, the $\mathrm{NH}_{2}$ (in SSPEI) amount of the nanoparticles was determined by 2,4,6-trinitrobenzene sulfonic acid assay. The amounts of protonable $\mathrm{NH}_{2}$ markedly increased with increasing feed ratios (Table 1), which reasonably explains why zeta potentials of the SSPEI-SPIO nanoparticles increased with increasing feed ratios. The SSPEI layer in the nanoparticles was further confirmed by Fourier transform infrared analysis. As revealed in Figure 2D, SSPEI60SPIO nanoparticles displayed two signals at the 1,650 and $2,825 \mathrm{~cm}^{-1}$, corresponding to the $\mathrm{O}=\mathrm{C}-\mathrm{OH}$ and $\mathrm{N}-\mathrm{CH}$ bending vibration, respectively. Moreover, the signals were also observed in the spectra of PAA-coated SPIO and SSPEI, thus implying that SSPEI-SPIO nanoparticles consist of both PAA and SSPEI residues. Overall, SSPEI-SPIO nanoparticles can be prepared successfully.

\section{SSPEI-SPIO nanoparticles mediate efficient gene release and transfection in vitro}

The complexation of SSPEI-SPIO nanoparticles and DNA was characterized at different mass ratios by dynamic light scattering analysis. It was found that these nanoparticles were capable of binding DNA to form nano-complexes at the mass ratios of 10:1 and 20:1 with average particle sizes below $150 \mathrm{~nm}$ and positive zeta potentials (Figure 2E, Table 2). Moreover, the complexes of SSPEI60-SPIO nanoparticles had smaller particle sizes and higher surface charges compared to those of SSPEI20-SPIO nanoparticles, indicating that SSPEI60-SPIO nanoparticles have higher gene binding ability.

Gene binding behavior of SSPEI-SPIO nanoparticles was also investigated by agarose gel retardation assay as a function of their mass ratios in the range from 0.5:1 to 20:1. All the nanoparticles showed a strong DNA binding at and above a mass ratio of 5:1, where complete DNA retardation was detected (Figure 3A). Moreover, among these nanoparticles, SSPEI60-SPIO nanoparticles again revealed the strongest gene binding as gene mobility is totally retarded at a mass ratio of $0.5: 1$, lower than 2:1 and 5:1 for the SSPEI20SPIO and SSPEI12-SPIO nanoparticles, respectively. This strong gene binding is due to the high surface charge of SSPEI60-SPIO nanoparticles $(26.3 \pm 0.5 \mathrm{mV}$, Table 1$)$.

Table 2 Characteristics of SSPEI-SPIO/DNA complexes at different mass ratios

\begin{tabular}{lllll}
\hline Code & Mass ratio & Size $(\mathbf{n m})$ & PDI & Zeta-potential $(\mathbf{m V})$ \\
\hline SSPEI20-SPIO & $10: 1$ & $160.4 \pm 5.3$ & 0.37 & $+3.1 \pm 2.2$ \\
& $20: 1$ & $135.2 \pm 2.7$ & 0.18 & $+13.2 \pm 1.6$ \\
SSPEI60-SPIO & $10: 1$ & $91.4 \pm 1.3$ & 0.27 & $+6.1 \pm 1.6$ \\
& $20: 1$ & $81.0 \pm 0.7$ & 0.17 & $+17.5 \pm 1.7$ \\
\hline
\end{tabular}

Abbreviations: SSPEI, disulfide-containing polyethylenimine; SPIO, superparamagnetic iron oxide; PDI, polydispersity index. 
The small particle sizes and high surface charge suggest that SSPEI60-SPIO nanoparticles are favorable for gene delivery and thus will be used in further study.

Our previous work showed that the SSPEI could mediate efficient DNA release from its polyplexes in a reducing environment due to the cleavage of the disulfide bond, thereby affording enhanced levels of gene expression. ${ }^{29,30}$ Herein, DNA release from SSPEI-SPIO/DNA complexes was examined by agarose gel retardation in 5 or $20 \mathrm{mM}$ DTT, mimicking an intracellular reducing environment. As expected, efficient DNA release was observed from the SSPEI60-SPIO/ DNA complexes at a mass ratio of $0.5: 1$ in $5 \mathrm{mM}$ DTT (Figure 3B). This release effect was more pronounced for the complexes at a mass ratio of $1: 1$ or 2:1 in the presence of $20 \mathrm{mM}$. The complexation of SSPEI60-SPIO and DNA was also evaluated by EB accessibility assay (Figure 3C). It was found that relative fluorescence $\left(\mathrm{F}_{\mathrm{REL}}\right)$ values of EB-DNA intercalate markedly reduced to $\sim 50 \%$ at SSPEI60-SPIO/ EB-DNA mass ratios ranging from 1:1 to 20:1, indicating the formation of SSPEI60-SPIO/EB-DNA complexes. However, the $\mathrm{F}_{\mathrm{REL}}$ values of the complexes recovered to $\sim 70 \%-90 \%$ upon exposure in the $20 \mathrm{mM}$ DTT, suggesting DNA dissociation from the complexes in a reducing environment.

Before SSPEI-SPIO nanoparticles were applied for DNA transfection, cytotoxicity was evaluated as a function of concentrations (Figure 4A). It was found that these nanoparticles, similar to SSPEI, had a low cytotoxicity profile in vitro against MCF-7 cells. For example, at the concentration of $50 \mu \mathrm{g} / \mathrm{mL}$, SSPEI, SSPEI20-SPIO and SSPEI60-SPIO nanoparticles all caused above $80 \%$ cell viability. However, non-degradable PEI led to $\sim 50 \%$ cell viability $(P<0.001)$. This low cytotoxicity for SSPEI-SPIO nanoparticles is most likely attributed to intracellular degradation of SSPEI, which diminishes charge density of the nanoparticles. By contrast, non-degradable PEI is known to have high charge density and induce cellular apoptosis as a result of its active interaction with mitochondrial membrane. ${ }^{31}$

Next, in vitro gene transfection of SSPEI60-SPIO nanoparticles was evaluated against MCF-7 cells using pCMV-GFP plasmid. The effect of SSPEI60-SPIO/DNA mass ratio on transfection efficiency was evaluated by the analysis of GFP expression levels (Figure 4B). In general, transfection efficiency of the nanoparticles first increased with increasing mass ratios from 0.5:1 to 5:1 and then leveled off until it reached the mass ratio of 20:1. SSPEI60-SPIObased complexes at the mass ratio of 5:1 yielded potent transfection with efficiency which is comparable to that of the complexes of branched PEI, one of the most potent
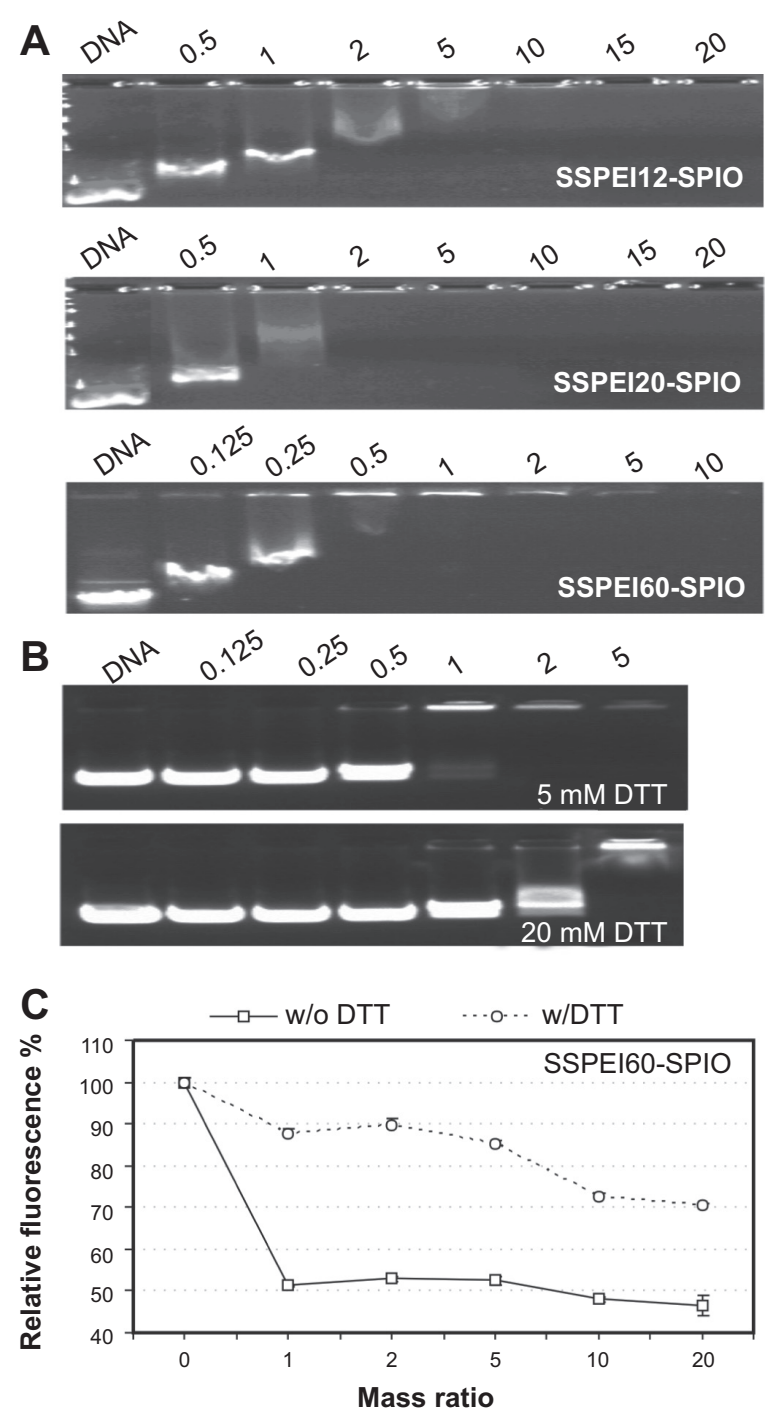

Figure 3 (A) Agarose gel retardation analysis of the complexes of SSPEII2-SPIO, SSPEI20-SPIO, and SSPEI60-SPIO at different mass ratios; (B) agarose gel retardation analysis of the complexes of SSPEI60-SPIO in 5 or 20 mM DTT; (C) EB accessibility assay of complexes of SSPEI60-SPIO/DNA at different mass ratios in the absence (w/o) and presence $(w /)$ of $20 \mathrm{mM}$ DTT.

Abbreviations: SSPEI, disulfide-containing polyethylenimine; SPIO, super para-magnetic iron oxide; DTT, dithiothreitol; EB, ethidium bromide; w/o, without; w/, with.

non-viral gene delivery vectors. Importantly, these SSPEI60SPIO-based complexes had low cytotoxicity at different mass ratios, with $\sim 100 \%$ cells maintaining their metabolic activity (Figure 4C). In parallel, branched PEI-based complexes induced mild cytotoxicity with $\sim 80 \%$ cell viability. Figures 4D and 4E exhibit transfected cells expressing GFP, observed under fluorescence microscopy, after SSPEI60SPIO nanoparticle-mediated transfection. The percentage of GFP-expressing $\left(\mathrm{GFP}^{+}\right)$cells was quantified using flow cytometry. The complexes based on SSPEI60-SPIO nanoparticles at an optimal mass ratio of 5:1 afforded efficient gene transfection in MCF-7, PC-3, HepG2 and SKOV-3 cells, ie, $20.5 \% \pm 1.3 \%, 33.8 \% \pm 3.1 \%, 45.5 \% \pm 3.1 \%$, and 

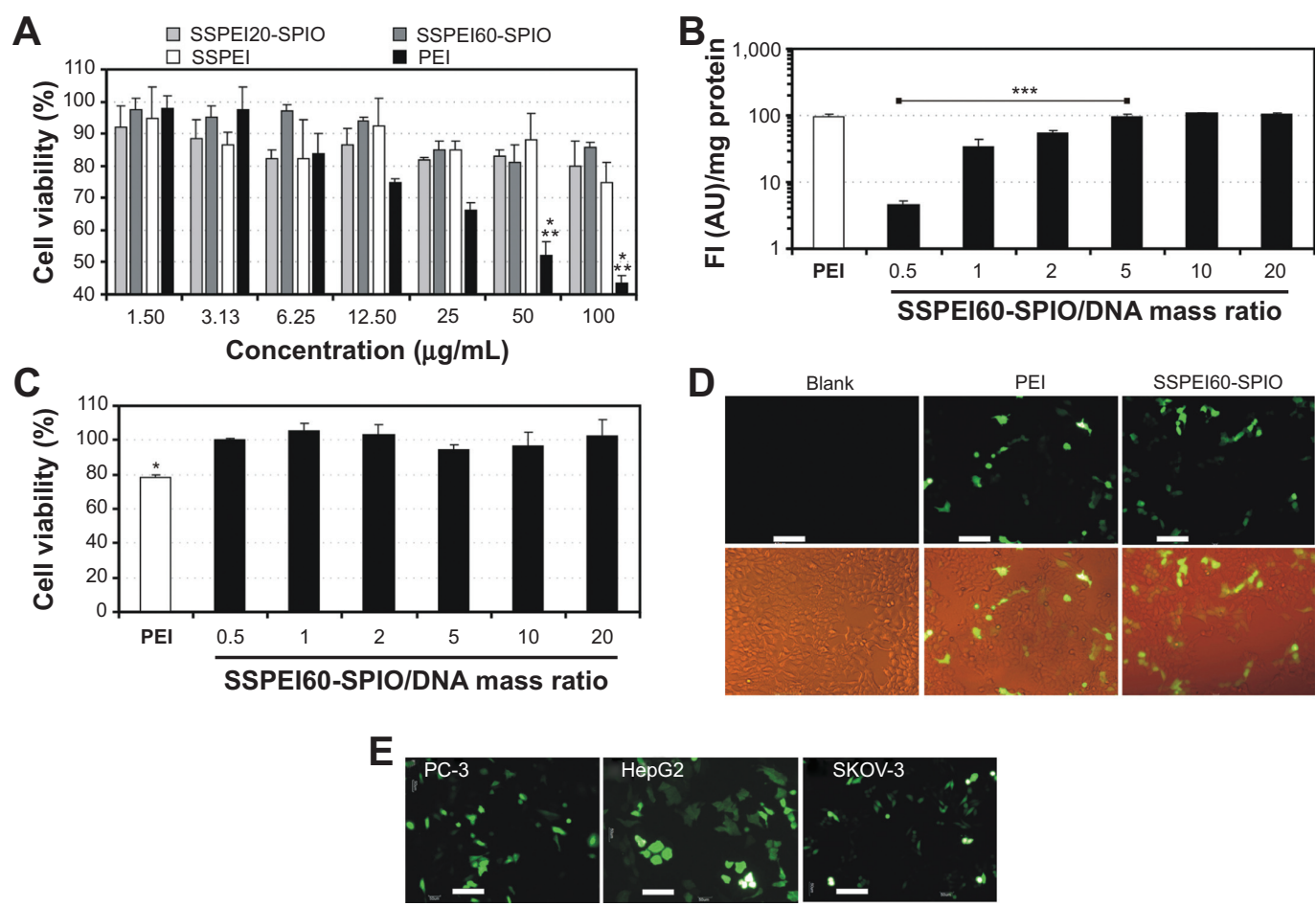

Figure 4 (A) Cytotoxicity evaluation of SSPEI-SPIO nanoparticles, SSPEI, and branched PEI against MCF-7 cells at varying concentrations. The percentage of relative cell viability was determined relative to control cells (untreated), taken as $100 \%$ cell viability (***P $<0.00$ I, SSPEI-SPIO, SSPEI versus PEI); (B,C) Gene expression levels and cell viability afforded by SSPEI60-SPIO/DNA in MCF-7 cells in vitro as a function of the mass ratios. The polyplexes of branched PEI at a mass ratio of I:I was used as a control. $* * * P<0.001$ and $* P<0.01$ : PEI versus blank; (D) Typical GFP-expressing MCF-7 cells observed under fluorescence microscopy after transfection with SSPEI60-SPIO nanoparticles and branched PEI; (E) GFP-expressing PC-3, HepG2 and SKOV-3 cells after transfection with SSPEI60-SPIO nanoparticles.

Note: scale bar: $50 \mu \mathrm{m}$.

Abbreviations: FI, fluorescence intensity; AU, arbitrary units; SSPEI, disulfide-containing polyethylenimine; SPIO, superparamagnetic iron oxide; PEI, polyethylenimine; GFP, green fluorescent protein.

$28.2 \% \pm 3.1 \% \mathrm{GFP}^{+}$cells, respectively. Overall, these results indicate that SSPEI-SPIO nanoparticles may serve as an efficient non-viral gene delivery carrier.

\section{SSPEI-SPIO nanoparticle-delivered hTERT-siRNA causes hTERT silencing and growth inhibition of HepG2 cells in vitro}

Because SSPEI60-SPIO nanoparticles are capable of DNA transfection in vitro against cancer cells, their utility for siRNA transfection was further studied to silence the hTERT gene. Our previous work showed that the SSPEI could bind siRNA to form nano-complexes to silence the hTERT gene in HepG 2 cells. ${ }^{30}$ Herein, we found that SSPEI60-SPIO nanoparticles were efficient to bind siRNA into nano-complexes at mass ratios of 10:1 and 20:1 with nanosized particle sizes $(<150 \mathrm{~nm})$ and positive surface charges (Table 3$)$. The results imply the possibility of SSPEI60-SPIO nanoparticles for siRNA delivery. Further, in vitro transfection assay using hTERT-siRNA showed that, among four hTERT-siRNAs, siRNA3 was able to downregulate the hTERT mRNA expression level in HepG2 cells, as determined by reverse transcription polymerase chain reaction assay (Figure 5A). Besides, the transfection of SSPEI60-SPIO/siRNA3 was successful in knocking down hTERT protein expression. The Western blot results (Figure 5B) indicated that, using $\beta$-actin as a reference, hTERT protein level was much lower in the siRNA3-treated group compared to the other three hTERT-siRNAs, siRNA-NC as well as the blank group. These results confirm that the SSPEI60-SPIO nanoparticle is capable of mediating efficient hTERT-siRNA delivery in HepG2 cells in vitro.

The effects of SSPEI60-SPIO/siRNA3-induced hTERT gene silencing on the activity of HepG2 cells were evaluated in terms of the cell viability and apoptosis. AlamarBlue ${ }^{\circledR}$ assay revealed that the complexes of SSPEI60-SPIO/ siRNA3 at the mass ratio of 10:1 exhibited an inhibitory

Table 3 Characteristics of SSPEI60-SPIO/siRNA complexes at varying mass ratios

\begin{tabular}{llll}
\hline Mass ratio & Size $(\mathbf{n m})$ & PDI & Zeta-potential $(\mathbf{m V})$ \\
\hline $10: 1$ & $103.5 \pm 2.0$ & 0.36 & $+8.24 \pm 1.3$ \\
$20: 1$ & $87.9 \pm 6.0$ & 0.28 & $+18.9 \pm 1.3$ \\
\hline
\end{tabular}

Abbreviations: SSPEI, disulfide-containing polyethylenimine; SPIO, super para-magnetic iron oxide; PDI, polydispersity index. 
A
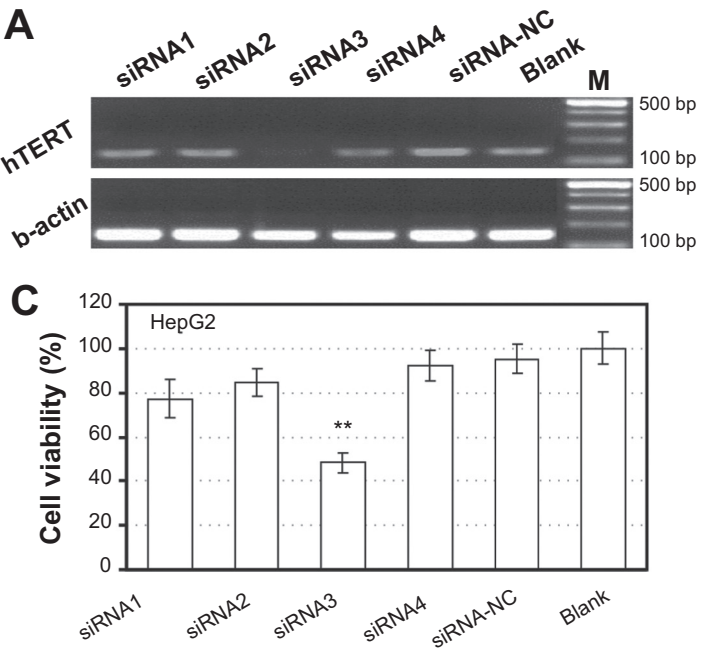

B
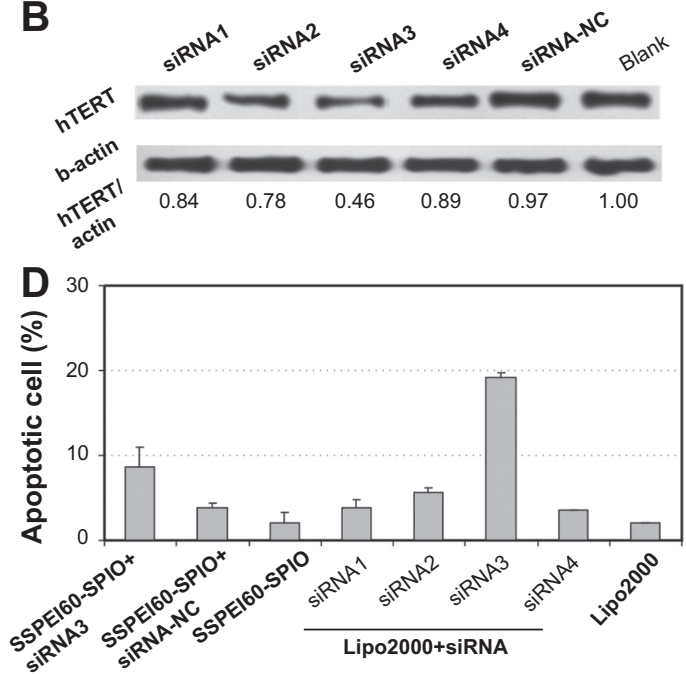

Figure 5 (A) RT-PCR for hTERT mRNA expression in HepG2 cells at 48 hours after a 4 hour exposure in the complexes of SSPEI60-SPIO/hTERT-siRNA (siRNA-NC) or untreated cells (blank) at the mass ratio of I0:I. The expression of the housekeeping gene $\beta$-actin was used as an internal control; (B) Western blot assay showing the expression of hTERT protein at 48 hours after a 4 hour exposure in SSPEI60/hTERT-siRNA or siRNA-NC (control) at the mass ratio of I0:I as well as untreated cells (blank), respectively. The expression of the housekeeping gene $\beta$-action was used as a reference. The semi-quantification of Western blot band intensity (mean $\times$ pixel) is shown as hTERT/ $\beta$-actin ratio and results are relative to the blank (taken as I.00); (C) effect of hTERT gene silencing induced by SSPEI60-SPIO/hTERT-siRNA complexes on HepG2 cell growth. ${ }^{*} * \mathrm{P}<0.01$ : siRNA3 versus blank; (D) effect of SSPEI60-SPIO/siRNA3-induced hTERT gene silencing on apoptosis in HepG2 cells. A formulation of Lipofectamine 2000/siRNA I-4 was used at an optimal ratio, SSPEI60-SPIO and Lipofectamine 2000 were used as controls.

Abbreviations: RT-PCR, reverse transcription polymerase chain reaction; siRNA, small interfering RNA; M, marker; hTERT, human telomerase reverse transcriptase; SSPEI, disulfide-containing polyethylenimine; SPIO, superparamagnetic iron oxide; Lipo2000, Lipofectamine 2000.

effect on the cell growth, with $48 \% \pm 3 \%$ viable cells compared to the untreated blank control (Figure 5C). It was expected that the cellular growth repression could be associated with cell apoptosis. As expected, the transfection with SSPEI60-SPIO/siRNA3 complexes induced significant apoptosis in HepG2 cells, that is, $8.5 \% \pm 2 \%$ apoptotic cells (Figure 5D). As a positive control, formulation of Lipo 2000/siRNA3 also led to a higher percentage of apoptotic cells $(18.5 \% \pm 1 \%)$. The apoptosis activity was not caused by SSPEI60-SPIO/siRNA-NC, SSPEI60SPIO, and Lipo 2000 alone. The formulation of Lipo 2000 with another three hTERT-siRNAs (ie, siRNA1, siRNA2 and siRNA4) induced low apoptosis $(<5 \%)$ in HepG2 cells, again indicating that the siRNA3 is more potent for hTERT-targeted therapy. Overall, the SSPEISPIO nanoparticle is a suitable carrier for the delivery of hTERT-siRNA towards cancer therapy.

\section{Near infrared and MR imaging of SSPEI-SPIO nanoparticles in tumor-bearing nude mouse}

In order to ascertain whether SSPEI-SPIO nanoparticles are applicable for tumor imaging, systemic distribution of SSPEI-SPIO nanoparticles was examined by an in vivo fluorescence imaging system (FMT 2500 ${ }^{\mathrm{TM}}$; PerkinElmer Inc.) after IV injection of Cy5.5-labeled SSPEI60-SPIO nanoparticles in a nude mouse bearing a HepG2 tumor. As shown in Figure 6A, the fluorescent nanoparticles could be detected in the tumor after 30 minutes post-injection and accumulated in the entire tumor at 60 minutes. The ex vivo imaging of the isolated tumor again confirmed the enrichment of the nanoparticles in the tumor. Moreover, the nanoparticles were found in other normal organs (ie, liver, spleen and kidney, Figure 6B). Accumulation kinetics of SSPEI60-SPIO nanoparticles in the tumor was further evaluated using in vivo imaging of the tumor and subsequent quantification assay of fluorescence intensity. It was found that accumulation amount of the nanoparticles in the tumor rapidly increased within 1 hour post-injection, leveled off until about 2 hours, and finally reduced markedly at 20 hours (Figure 6C). At 20 hours post-injection, the nanoparticles were mainly located in the liver $(6.10 \% \pm 1.5 \%)$ and spleen $(2.82 \% \pm 0.1 \%)$ by ex vivo imaging analysis of isolated organs (Figure $6 \mathrm{D}$ ). Although only $1.23 \% \pm 0.1 \%$ of the nanoparticles was found in the tumor, this content was higher as compared to that of Cy5.5 alone as a control $(0.3 \% \pm 0.02 \%, P<0.01)$, when the same Cy5.5 dose is used for the nanoparticle and Cy5.5 group, respectively. Additionally, free Cy5.5 was eliminated more rapidly by the liver and spleen with a higher amount as compared to the nanoparticles at the 20 hour time point, that is, $20.26 \%$ versus $6.10 \%$ in the liver and $4.47 \%$ versus $2.82 \%$ in the spleen. This different accumulation result 

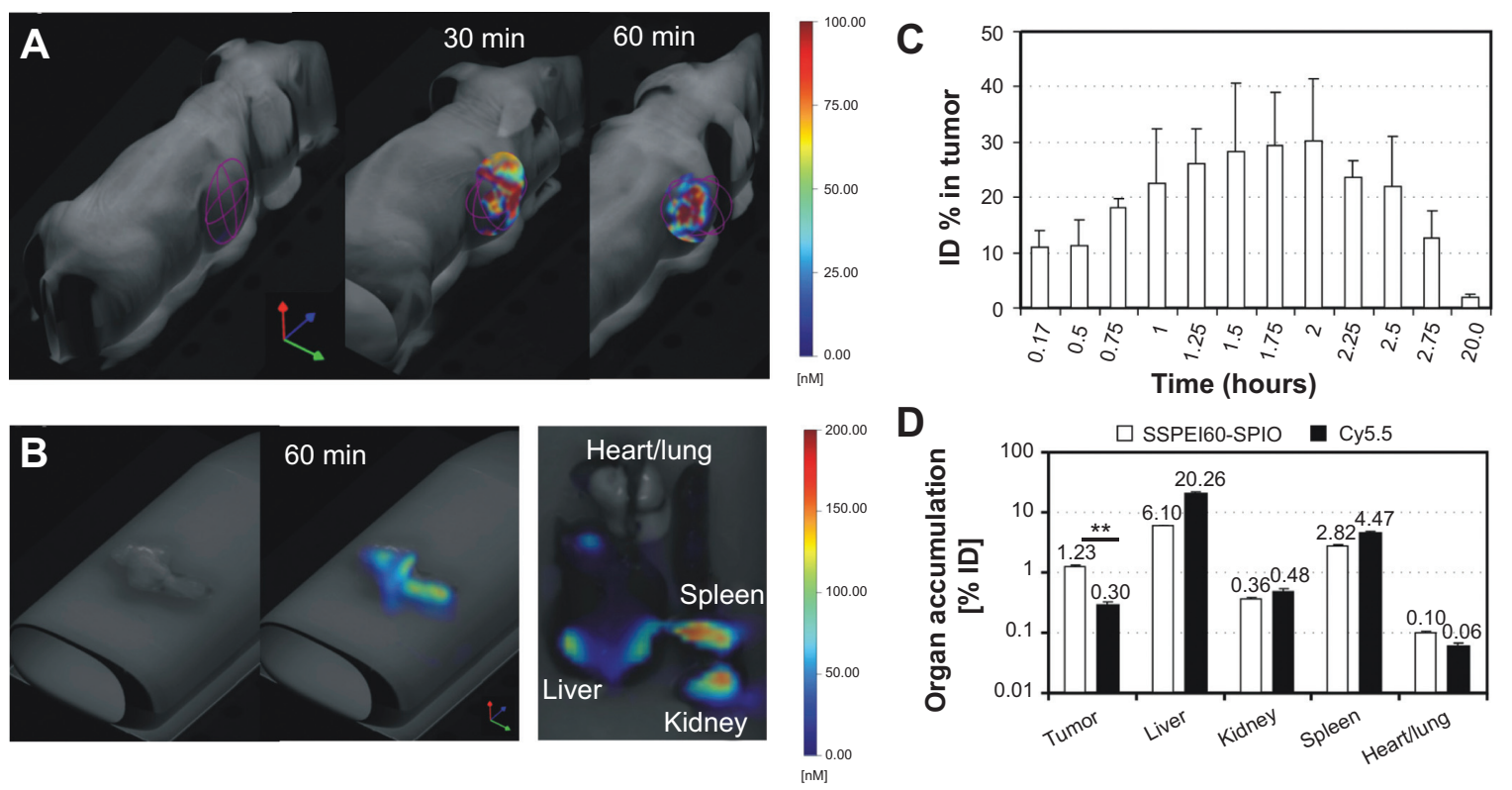

Figure 6 (A) In vivo near infrared imaging of Cy5.5-labeled SSPEI60-SPIO nanoparticles in HepG2 tumor bearing in nude mice at different time intervals; (B) ex vivo imaging of Cy5.5-labeled SSPEI60-SPIO nanoparticles in tumor and organs after 60 minutes post-injection; (C) accumulation kinetics of Cy5.5-SSPEI60-SPIO nanoparticles in tumor after post-injection at different times; (D) body biodistribution of Cy5.5-labeled SSPEI-SPIO nanoparticles or Cy5.5 24 hours post-injection.

Note: $* * P<0.05$.

Abbreviations: ID \%, percentage of injection dose; SSPEl, disulfide-containing polyethylenimine; SPIO, superparamagnetic iron oxide; min, minutes.

is probably due to the "enhanced permeability and retention" effect for nanoparticles which preferentially accumulate in the tumor with leaky vasculature.

Because the SSPEI-SPIO nanoparticles comprise a SPIO core, they are expected to be practical as T2-negative contrast agents for MR imaging. First, the magnetization property of SSPEI-SPIO nanoparticles was characterized by a vibrating sample magnetometer in an applied magnetic field of $\pm 5 \mathrm{k}$ Oe at room temperature. As shown in Figure 7A, SSPEI60SPIO nanoparticles showed a superparamagnetic property, revealing no change in magnetism after SSPEI decoration of PAA-coated SPIO nanoparticles. Next, SSPEI60-SPIO nanoparticles were dispersed in agarose gels at different $\mathrm{Fe}$ concentrations and the gels were analyzed by MR imaging. Figure 7B gives visual contrast phantom and quantitative relaxation time (T2) of these gels. It was indicated that the SSPEI60-SPIO nanoparticle was efficient as a T2-negative contrast agent for MR imaging. The relaxivity (defined as the slope of T2 versus Fe concentration) of SSPEI60-SPIO nanoparticles was found to be $97.6 \mathrm{mM}^{-1} \mathrm{~s}^{-1}$, which is comparable to that of Resovist $\left(95.2 \mathrm{mM}^{-1} \mathrm{~s}^{-1}\right),{ }^{32}$ a commercial SPIO-based contrast agent as a positive control. Further, an in vivo MR imaging study revealed that, at 1 to 3 hours post-IV injection of SSPEI60-SPIO nanoparticles in a nude mouse bearing a HepG2 tumor, the signal intensity on a T2-weighted fast spin echo image of the tumor significantly reduced (Figure 7C), indicating accumulation of the nanoparticles in the tumor. Support data are also provided by ex vivo Prussian blue staining of the isolated tumor, showing that the nanoparticles are located in the tumor and also other organs such as the spleen, lung, and kidney (Figure 7D).

\section{Discussion}

Theranostic nanoparticles offer a multifunctional platform for human cancer diagnosis and therapy. Because of their acceptable biocompatibility and practical surface modifications, SPIO-based nanoparticles become appealing theranostic agents for cancer imaging and therapy. In this study, we develop the preparation of a theranostic nano-system based on SSPEI-coated SPIO nanoparticles which have dual functions in nucleic acid delivery and MR imaging. An appealing nature of the SSPEI-SPIO nanoparticles is their water-soluble, disulfide-based PEI outer layer which provides a positive surface charge for efficient gene binding and subsequent gene release in response to an intracellular reducing environment. Although many SPIO nanoparticles coated by $\mathrm{PEI}^{17,26}$ and polyamidoamine dendrimers ${ }^{33}$ were investigated for non-viral gene delivery, these systems were normally not capable of mediating intracellular gene release. This indispensable gene release process is identified as one of the major gene delivery barriers. ${ }^{34}$ To address this issue, recent research ${ }^{11}$ and our previous work ${ }^{14,29}$ have focused on intracellular gene/siRNA release mediated by disulfide-based cationic polymers. Herein, the SSPEI 

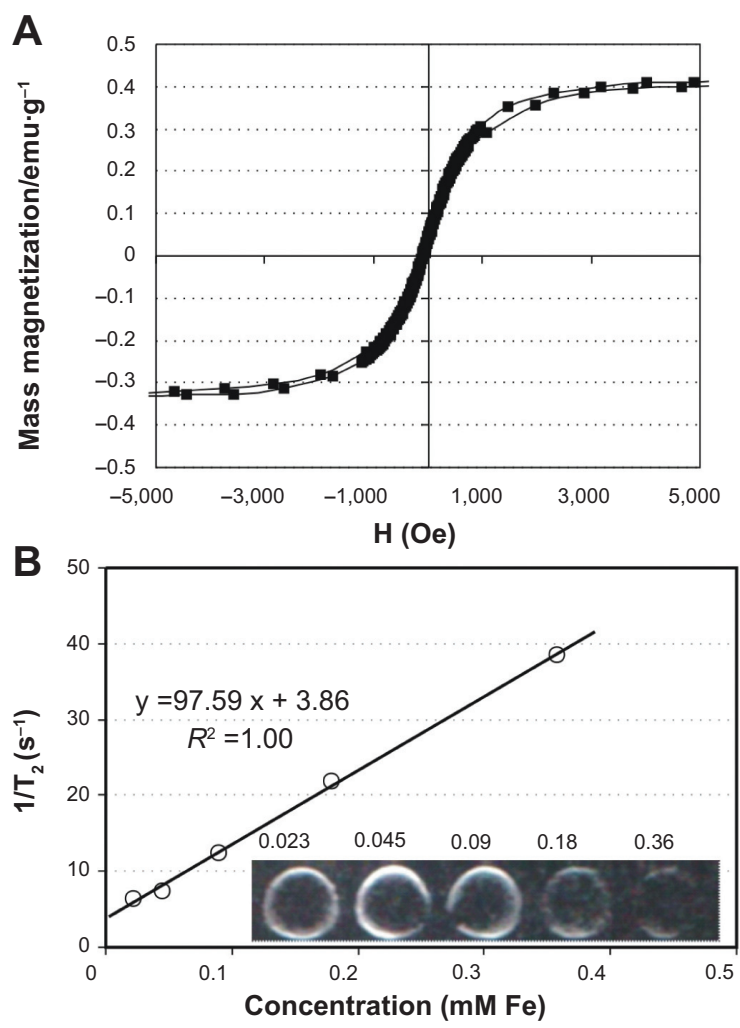

C

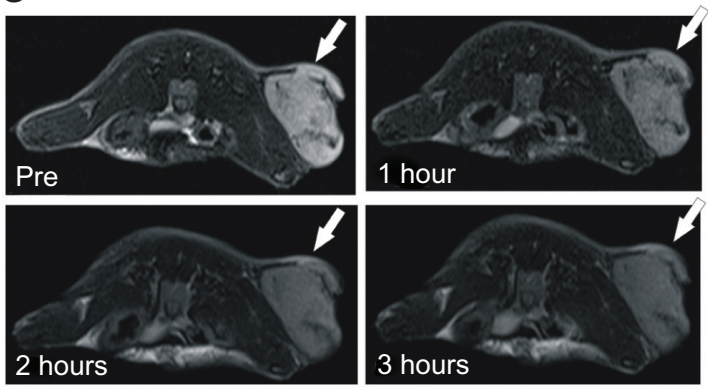

D
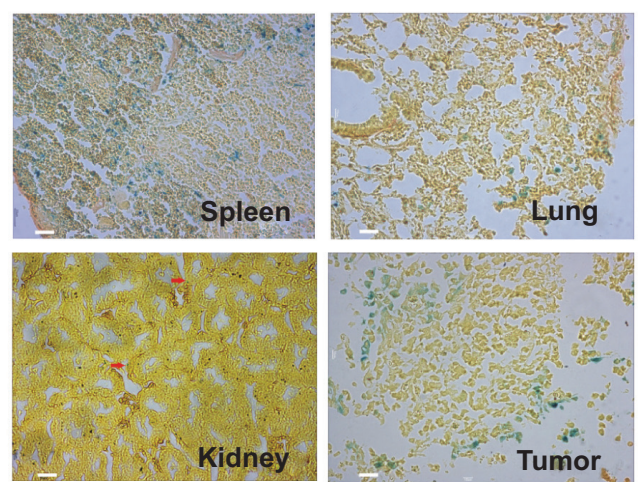

Figure 7 (A) Magnetization curves of SSPEI60-SPIO nanoparticles; (B) phantom images and quantified MR signal intensity of SSPEI60-SPIO nanoparticles encapsulated in 0.7\% agarose gel at different Fe concentrations; (C) in vivo MR images of tumor-xenografted nude mice of SSPEI60-SPIO nanoparticles before (pre) and at I, 2, and 3 hours post-IV injection. The arrows indicate tumor location; (D) Prussian blue staining of tissue sections 4 hours after IV injection of SSPEI60-SPIO nanoparticles.

Abbreviations: $\mathrm{H}$, magnetic intensity; $\mathrm{T}_{2}$, relaxation time; MR, magnetic resonance; SSPEI, disulfide-containing polyethylenimine; SPIO, superparamagnetic iron oxide; IV, intravenous.

outer layer of SSPEI-SPIO nanoparticles again reveals the ability to mediate redox-triggered gene delivery as confirmed by agarose gel retardation and DNA accessibility assay (Figures 3B-C), suggesting that the SSPEI could be degraded in the cell interior by the cleavage of a disulfide bond, thereby causing a facilitated intracellular gene release. These favorable gene delivery properties such as strong DNA/siRNA binding, positive surface charge, and facilitated gene release, combined with low cytotoxicity of SSPEI60-SPIO nanoparticles (Figure 4A), may reasonably interpret why they are capable of inducing high transfection or silencing efficiency (Figures 4 and 5). Therefore, integration of SSPEI with SPIO nanoparticles provides a "smart" nano-system for efficient nucleic acid delivery. It may be deduced that this integration concept could be practical to other nanoparticles for drug delivery purposes. To the best of our knowledge, this is the first report on disulfide-based cationic polymer-coated SPIO nanoparticles for reductiontriggered gene delivery.

As a core component of telomerase, hTERT is an attractive anticancer target for human cancer therapy ${ }^{35}$ since hTERT mRNA is highly expressed in almost all types of human cancer cells but not in normal human somatic cells. ${ }^{36-38}$ Although hTERT-siRNA delivery with lipids and cationic polymers was reported previously, ${ }^{39-41}$ this is the first report on cationic nanoparticles for hTERT-siRNA delivery. SSPEI-SPIO nanoparticles are able to mediate hTERTsiRNA delivery in vitro, causing downregulation of hTERT $\mathrm{mRNA}$ /protein expression as well as reduced cell viability in HepG2 cells due to their rapid apoptosis (Figure 5D). In the previous study, hTERT was identified to play a pivotal role in gene stabilization and DNA repair in cancer cells. ${ }^{42}$ For this reason, we deduce that significant silencing of hTERT by the complexes of SSPEI60-SPIO/hTERTsiRNA3 in HepG2 cells will damage the cellular functions, thereby inducing their apoptosis and death. Besides, a rational sequence design of siRNA is indispensable for efficient gene silencing. Herein, four hTERT-siRNA sequences induce different gene silencing efficiencies (Figure 5A and 5B). A few attributes of siRNA sequences such as low $\mathrm{G} / \mathrm{C}$ content $(30 \%-52 \%)$ can favorably contribute to siRNA activity. ${ }^{43}$ Herein, the hTERT-siRNA3 reveals relatively low G/C content (47\%), which may be responsible for efficient hTERT gene knockdown. Also, other parameters of siRNA sequences including thermal stability, base position preferences in sense strand and the lack of inverted base repeats could have an 
effect on siRNA activity, ${ }^{43,44}$ thus yielding different levels of hTERT gene silencing (Figure 5A).

Systematic evaluation of SSPEI-SPIO nanoparticles for in vivo gene delivery should be done in further studies. Biodistribution experiment reveals that the nanoparticles generally accumulated in the liver, spleen, and kidneys after IV injection of Cy5.5-labeled SSPEI-SPIO nanoparticles by tail-vein injection (Figure 6 and 7D). The retention in the liver and spleen is caused by their opsonization, a process where the antibodies in the bloodstream interact with positively-charged nanoparticles and are then recognized by the phagocytic cells. ${ }^{45}$ Accordingly, the SSPEI-SPIO nanoparticles are more suited for tumor therapy by local injection of their therapeutic complexes. Our previous reports also showed positive anti-tumor efficacy with siRNA-induced hTERT or VEGF silencing by intratumoral injection of SSPEI/siRNA complexes. ${ }^{13,14}$ In future work, modification of SSPEI-SPIO nanoparticles with poly(ethylene glycol) or ligands will be performed to offer the theranostic nanoparticles with "stealth" and targeting ability for intravenous gene delivery with minimized accumulation in normal organs and long-term circulation. ${ }^{46-49}$

\section{Conclusion}

We have revealed that SSPEI-SPIO nanoparticles can be readily obtained and applied for reduction-triggered plasmid DNA release against cancer cells. The amount of SSPEI in SSPEI-SPIO nanoparticles can be adjusted by varying the feed ratio of SSPEI and SPIO. Moreover, SSPEI-SPIOdelivered hTERT-siRNA can efficiently suppress hTERT mRNA expression against HepG2 cells, causing cellular growth inhibition. Further, SSPEI-SPIO nanoparticles are applicable as T2-negative contrast agents for MR tumor imaging in vivo. Thus, SSPEI-SPIO nanoparticles have great promise for tumor gene therapy and imaging.

\section{Acknowledgments}

This article is supported by the grants from the Shanghai Municipal Natural Science Foundation (13ZR1443600, CL), Ministry of Science and Technology of China (973 program) (2012CB966300, 2014CB964600, PZ), National High Technology Research and Development Program of China (863 Program) (2013AA032202, CL) and Fundamental Research Funds for the Central Universities (CL) the National Natural Science Funds of China (81271369, 8137195, 81250110578 to PZ, ZL, BP).

\section{Author contributions}

Dan Li and Xin Tang contributed equally to this work and thus both are co-first authors. All authors contributed toward data analysis, drafting, and revising the paper and agree to be accountable for all aspects of the work.

\section{Disclosure}

The authors report no conflicts of interest in this work.

\section{References}

1. Anderson WF. Human gene therapy. Nature. 1998;392:25-30.

2. Luten J, van Nostrum CF, De Smedt SC, Hennink WE. Biodegradable polymers as non-viral carriers for plasmid DNA delivery. $J$ Controlled Release. 2008;126(2):97-110.

3. Li S, Huang L. Non-viral gene therapy: promises and challenges. Gene Ther. 2000;7:31-34.

4. Pack DW, Hoffman AS, Pun S, Stayton PS. Design and development of polymers for gene delivery. Nat Rev Drug Discov. 2005;4(7): 589-593.

5. Patnaik S, Gupta KC. Novel polyethylenimine-derived nanoparticles for in vivo gene delivery. Expert Opin Drug Deliv. 2013;10(2):215-228.

6. Panyam J, Labhasetwar V. Biodegradable nanoparticles for drug and gene delivery to cells and tissue. Adv Drug Delivy Rev. 2003;55(3): 329-347.

7. Jones $\mathrm{CH}$, Chen CK, Ravikrishnan A, Rane S, Pfeifer BA. Overcoming nonviral gene delivery barriers: perspective and future. Mol Pharm. 2013;10(11):4082-4098.

8. Ghilardi A, Pezzoli D, Bellucci MC, et al. Synthesis of multifunctional PAMAM-aminoglycoside conjugates with enhanced transfection efficiency. Bioconjug Chem. 2013;24(11):1928-1936.

9. Boussif O, Lezoualc'h F, Zanta MA, et al. A versatile vector for gene and oligonucleotide transfer into cells in culture and in vivo polyethylenimine. Proc Natl Acad Sci U S A. 1995;92(16): 7297-7301.

10. Cheng R, Feng F, Meng FH, Deng C, Feijen J, Zhong Z. Glutathione-responsive nano-vehicles as a promising platform for targeted intracellular drug and gene delivery. $J$ Controlled Release. 2011;152(1):2-12.

11. Son S, Namgung R, Kim J, Singha K, Kim WJ. Bioreducible polymers for gene silencing and delivery. Acc Chem Res. 2012;45(7): $1100-1112$.

12. Zhang GY, Liu J, Yang Q, Zhuo R, Jiang X. Disulfide-containing brushed polyethylenimine derivative synthesized by click chemistry for nonviral gene delivery. Bioconjug Chem. 2012;23(6): $1290-1299$.

13. Xia W, Wang P, Lin C, et al. Bioreducible polyethylenimine-delivered siRNA targeting human telomerase reverse transcriptase inhibits HepG2 cell growth in vitro and in vivo. J Control Release. 2012;157(3): 427-436.

14. Xia W, Li Y, Lou B, Wang PJ, Gao XL, Lin C. Bioreducible PEI-siRNA nanocomplex for liver cancer therapy: transfection, biodistribution, and tumor growth inhibition in vivo. J Nanomater. 2013:ID 384717.

15. Shi Y, Zhou L, Wang R, et al. In situ preparation of magnetic nonviral gene vectors and magnetofection in vitro. Nanotechnology. 2010; 21(11):115103.

16. Veiseh $\mathrm{O}$, Kievit FM, Liu V, et al. In vivo safety evaluation of polyarginine coated magnetic nanovectors. Mol Pharm. 2013;10(11):4099-4106.

17. Chertok B, David AE, Yang VC. Polyethyleneimine-modified iron oxide nanoparticles for brain tumor drug delivery using magnetic targeting and intra-carotid administration. Biomaterials. 2010;31(24): $6317-6324$

18. Kievit FM, Veiseh O, Bhattarai N, et al. PEI-PEG-Chitosan Copolymer Coated Iron Oxide Nanoparticles for Safe Gene Delivery: synthesis, complexation, and transfection. Adv Funct Mater. 2009;19(14): 2244-2251.

19. Chen Y, Wang W, Lian G, et al. Development of an MRI-visible nonviral vector for siRNA delivery targeting gastric cancer. Int $J$ Nanomedicine. 2012;7:359-368. 
20. Wang C, Ravi S, Garapati US, et al. Multifunctional chitosan magneticgraphene $(\mathrm{CMG})$ nanoparticles: a theranostic platform for tumortargeted co-delivery of drugs, genes and MRI contrast agents. J Mater Chem B. 2013;1(35):4396-4405.

21. Wan Q, Xie L, Gao L, et al. Self-assembled magnetic theranostic nanoparticles for highly sensitive MRI of minicircle DNA delivery. Nanoscale. 2013;5(2):744-752.

22. Yang X, Hong H, Grailer JJ, et al. cRGD-functionalized, DOXconjugated, and ${ }^{64} \mathrm{Cu}$-labeled superparamagnetic iron oxide nanoparticles for targeted anticancer drug delivery and PET/MR imaging. Biomaterials. 2011;32(17):4151-4160.

23. Yang X, Grailer JJ, Rowland IJ, et al. Multifunctional SPIO/DOXloaded wormlike polymer vesicles for cancer therapy and MR imaging. Biomaterials. 2010;31(34):9065-9073.

24. Yang X, Pilla S, Grailer JJ, et al. Tumor-targeting, superparamagnetic polymeric vesicles as highly efficient MRI contrast probes. J Mater Chem. 2009;19(32):5812-5817.

25. Ge J, Hu Y, Biasini M, et al. One-step synthesis of highly watersoluble magnetite colloidal nanocrystals. Chemistry. 2007;13(25): 7153-7161.

26. Lin C, Ge J. Multifunctional polyethylenimine-conjugated superparamagnetic nanoparticles for drug delivery and imaging. J Control Release. 2011;152 Suppl 1:e58-e60.

27. Lin C, Engbersen JFJ. PEGylated bioreducible poly(amido amine)s for non-viral gene delivery. Mater Sci Eng C. 2011;31(7):1330-1337.

28. Lin C, Zhao P, Li F, Guo F, Li Z, Wen X. Thermosensitive in situforming dextran-pluronic hydrogels through Michael addition. Mater Sci Eng C. 2010;30(8):1236-1244.

29. Lin C, Zhong Z, Lok MC, et al. Novel bioreducible poly(amido amine)s for highly efficient gene delivery. Bioconjug Chem. 2007;18: $138-145$.

30. Lin C, Blaauboer CJ, Timoneda MM, et al. Bioreducible poly(amido amine)s with oligoamine side chains: synthesis, characterization, and structural effect on gene delivery. J Control Release. 2008;126(2): 166-174.

31. Moghimi SM, Symonds P, Murray JC, Hunter AC, Debska G, Szewczyk A. A two-stage poly(ethylenimine)-mediated cytotoxicity: Implications for gene transfer/therapy. Mol Ther. 2005;11(6): 990-995

32. Hua MY, Yang HW, Liu H-L, et al. Superhigh-magnetization nanocarrier as a doxorubicin delivery platform for magnetic targeting therapy. Biomaterials. 2011;32(34):8999-9010.

33. Pan B, Cui D, Sheng Y, et al. Dendrimer-modified magnetic nanoparticles enhance efficiency of gene delivery system. Cancer Res. 2007; 67(17):8156-8163.

34. Schaffer DV, Fidelman NA, Dan N, Lauffenburger DA. Vector unpacking as a potential barrier for receptor-mediated polyplex gene delivery. Biotechnol Bioeng. 2000;67(5):598-606.
35. Xia W, Lin C. Bioreducible polymer-delivered siRNA targeting human telomerase reverse transcriptase for human cancer gene therapy. Ther Deliv. 2012;3(4):439-442.

36. Morin GB. The human telomerase terminal transferase enzyme is a ribonucleoprotein that synthesizes TTAGGG repeats. Cell. 1989;59(3): 521-529.

37. Shay JW, Zou Y, Hiyama E, Wright WE. Telomerase and cancer. Hum Mol Genet. 2001;10(7):677-685.

38. Philippi C, Loretz B, Schaefer UF, Lehr CM. Telomerase as an emerging target to fight cancer-opportunities and challenges for nanomedicine J Control Release. 2010;146(2):228-240.

39. Liu X, Huang H, Wang J, et al. Dendrimers-delivered short hairpin RNA targeting hTERT inhibits oral cancer cell growth in vitro and in vivo. Biochem Pharmacol. 2011;82(1):17-23.

40. Gandellini P, Folini M, Bandiera R, et al. Down-regulation of human telomerase reverse transcriptase through specific activation of RNAi pathway quickly results in cancer cell growth impairment. Biochem Pharmacol. 2007;73(11):1703-1714.

41. Dong X, Liu A, Zer C, et al. siRNA inhibition of telomerase enhances the anti-cancer effect of doxorubicin in breast cancer cells. BMC Cancer 2009;9:133

42. Sharma GG, Gupta A, Wang H, et al. hTERT associates with human telomeres and enhances genomic stability and DNA repair. Oncogene. 2003;22(1):131-146.

43. Reynolds A, Leake D, Boese Q, Scaringe S, Marshall WS, Khvorova A. Rational siRNA design for RNA interference. Nat Biotechnol. 2004; 22(3):326-330.

44. Wang LQ, Mu FY. A Web-based design center for vector-based siRNA and siRNA cassette. Bioinformatics. 2004;20(11):1818-1820.

45. Plank C, Mechtler K, Szoka FC, Wagner E. Activation of the complement system by synthetic DNA complexes: a potential barrier for intravenous gene delivery. Hum Gene Ther. 1996;7(12):1437-1446.

46. Han HS, Lee J, Kim HR, et al. Robust PEGylated hyaluronic acid nanoparticles as the carrier of doxorubicin: mineralization and its effect on tumor targetability in vivo. J Control Release. 2013;168(2): $105-114$.

47. El-Dakdouki MH, El-Boubbou K, Zhu DC, Huang X. A simple method for the synthesis of hyaluronic acid coated magnetic nanoparticles for highly efficient cell labelling and in vivo imaging. RSC Adv. 2011;1(8): 1449-1452.

48. Kamat M, El-Boubbou K, Zhu DC, et al. Hyaluronic acid immobilized magnetic nanoparticles for active targeting and imaging of macrophages. Bioconjug Chem. 2010;21(11):2128-2135.

49. Lin C, Song YY, Lou B, Zhao P. Dextranation of bioreducible cationic polyamide for systemic gene delivery. Biomed Mater Eng. 2014;24(1): 673-682.
International Journal of Nanomedicine

\section{Publish your work in this journal}

The International Journal of Nanomedicine is an international, peerreviewed journal focusing on the application of nanotechnology in diagnostics, therapeutics, and drug delivery systems throughout the biomedical field. This journal is indexed on PubMed Central,

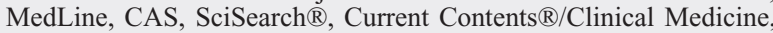

\section{Dovepress}

Journal Citation Reports/Science Edition, EMBase, Scopus and the Elsevier Bibliographic databases. The manuscript management system is completely online and includes a very quick and fair peer-review system, which is all easy to use. Visit http://www.dovepress.com/ testimonials.php to read real quotes from published authors. 